\title{
Medicinal Plant Recognition of Leaf Shape using Localized Arc Pattern Method
}

\author{
Ni Kadek Ayu Wirdiani ${ }^{\# 1}$, A.A.K. Oka Sudana ${ }^{\# 2}$ \\ \# Information Technology Department, Faculty of Engineering, Udayana University \\ Jimbaran, Bali, Indonesia \\ 1ªyuwirdiani@unud.ac.id \\ 22agungokas@unud.ac.id
}

\begin{abstract}
Medicinal plants are plants that have benefit in order to supply the needs of families traditionally medicine. Medicinal plants have diverse types that causing modern society have difficulty in recognizing these crops. Medicinal plants generally can be identified by the leaves, stems and fruit. One of the leaves characteristics can be distinguished based on vein structure and shape of its. Based on these problem, plant recognition based on vein and shape are made by using Localized Arc Pattern Method.

There are two important processes in Plant Recognition Applications. First process is Enrollment and the second is Recognition process. In the Enrolment process, the leaves image filed as many as 6 images for each leaves type. This image then calculated based on the 42 special model pattern obtained and the feature is stored as a reference image. Leaves images that used as test image are 200 images. On the Recognition process, the test image will be process which as same as at Enrollment process, however feature from the test image will be comparing with reference image in database, then it calculate the difference value. This process uses a threshold value to determine whether the test images leaves are recognized or not. When dissimilarity value is smaller than the threshold is known as the same leaves, when instead then it known as a different leaves or not known at all. Experiment result shows in this application can recognize $77 \%$ of total leaves and False Accepted Ratio (FAR) equal to $4.5 \%$ and False Rejection Ratio (FRR) equal to $18.5 \%$. This result was influenced by the shiny surface of leaf and shape of the leaves are small.
\end{abstract}

Keyword: Medicinal Plant Recognition, Leaf Recognition, Localized Arc Pattern, feature extraction, matching process, dissimilarity value, FAR, FRR.

\section{INTRODUCTION}

Modern society began seriously to think about health issues because in a healthy body there is a healthy soul anyway. Food products consumed began turning to organic food and medication used also have started with the use of herbal medicines. Family Medicinal Plants include herbs are easy to be got and easy to be developed in Indonesia. Types of medicinal plants is quite a lot, causing modern society would be difficult to recognize and remember these crops. Family Medicinal Plants generally can be identified by the leaves, stems and fruit. One of its characteristics can be distinguished by the bones and the shape. Pursuant on these problems, application of plant recognition is made based on vein and leaf shape using Localized Arc Pattern Method.

Plant recognition of leaves shape is using image processing as an initial processing, which image input leaves is converted into binary image then would be processed further to find the feature. There are many method that can be used to compute the feature extraction as well as the introduction of plants by identifying the shape $[1,8]$, segment [2], color [6] and the texture of the leaves [3,4,5]. Research that using Localized Arc Pattern method is a research for palms recognition and signature verification [9,10]. Palms and leaves vein has the same shape characteristic. Accuration result of palm prints research is about $94 \%$ and signature verification is about $90.3 \%$. This research will be made the introduction of Plants using Localized Arc Pattern method have made a success of recognition for the palm prints and signature verification. This research expected can assist common society to know more about the names of plants based on shape and leaf segments.

\section{RESEACH METHOD}

This study begins with the collection of leaves types which taken directly from multiple locations. Leaves sample consist of 10 types with the composition of each types is 30 leaves. The composition is consist of : leaves of papaya, leaves of Guava, leaves of Dadap, leaves of Sirih, leaves of Kumis Kucing, leaves of Mengkudu, leaves of Salam, leaves of Sembung, leaves of Samiloto and leaves of Soursop. Each leaf was photographed with the image size 1728 x 3072 pixel then it converted into 300 x 300 pixels. Leaves references used in this study is 60 images of leaves, the test images to determine threshold value use 40 images while the 
number of test images for recognition is 200 images. The image below shows a general overview Plant Recognition Application.

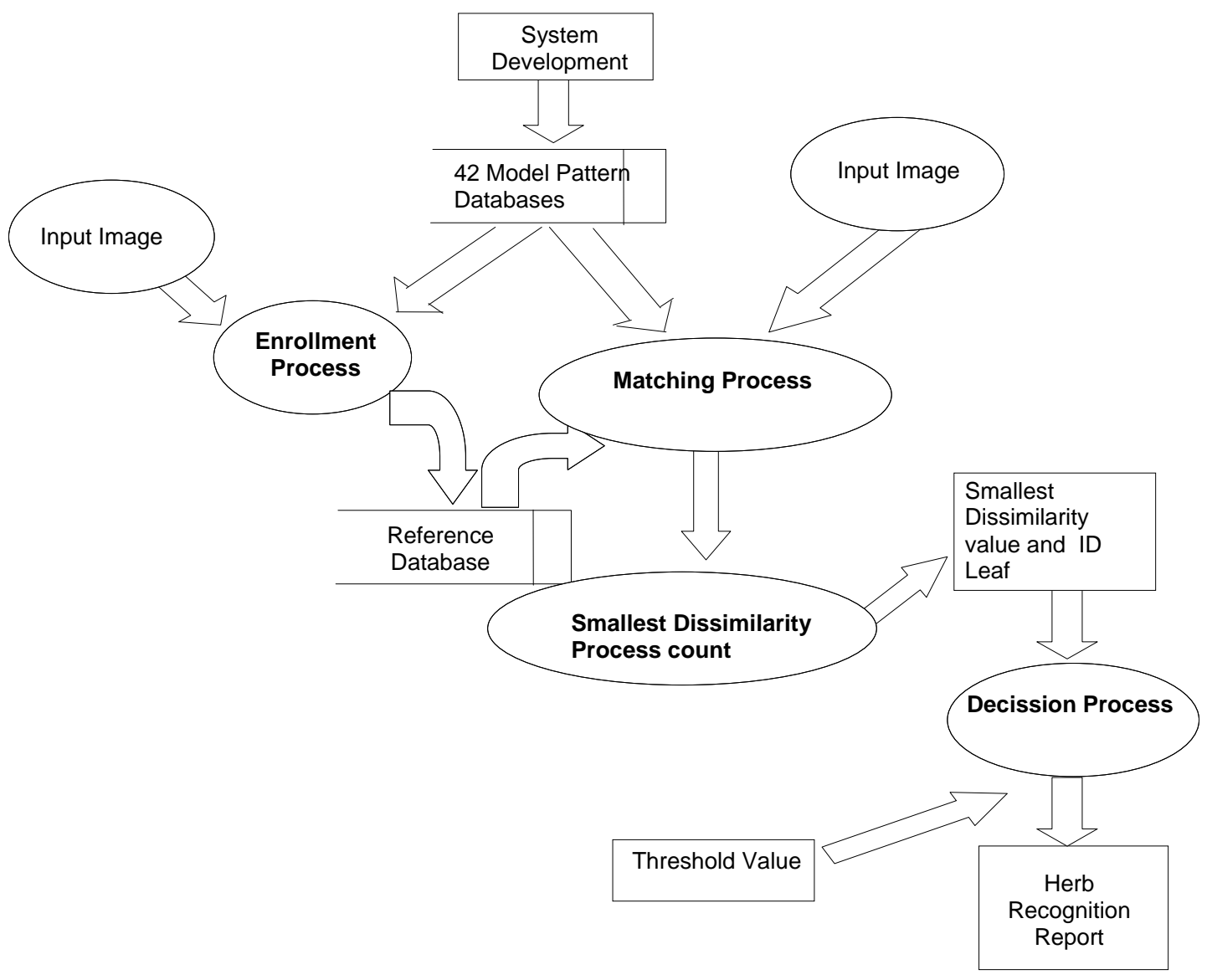

Fig1.Description of Plant Recognition Process

The stages are carried out in Medicinal Plant Recognition of Leaf Shape using Localized Arc Pattern Method are as follows:

\section{A. Data acquisition}

Data acquisition is data retrieval process of image leaf image by using a camera phone with resolution 4.1 mega pixel with distance of picture as high as $30 \mathrm{~cm}$.

\section{B. Preprocessing}

Preprocessing process start by turn color input image into grayscale. Input color image will be change to grayscale by using formula [11]:

$$
\mathrm{G}(x, y)=(\mathrm{R}+\mathrm{G}+\mathrm{B}) / 3
$$

Grayscale value for each image pixel is obtained by calculating the average value from the color values of R (red), G (green), and B (blue) on each pixel.

Grayscale image will be filter to eliminate obtained noise at the intake of picture by using Median Filter. Next process is detecting edge by using Prewitt method to get leaf bone which later will be used on process feature extraction. This method takes the principle of Laplacian function known as a function for generating High Pass Filter. Kernel filters used in Prewitt method is [11] which perform a search in horizontal $(\mathrm{H})$ and vertical $(\mathrm{V})$.: 


$$
\begin{aligned}
& H=\left[\begin{array}{lll}
-1 & 0 & 1 \\
-1 & 0 & 1 \\
-1 & 0 & 1
\end{array}\right] \\
& V=\left[\begin{array}{ccc}
1 & 1 & 1 \\
0 & 0 & 0 \\
1 & 1 & 1
\end{array}\right]
\end{aligned}
$$

Next step is convert the image to binarization process. This method using the ratio of gray level value to obtain threshold value automatically. If the grayscale value less than or equal to the threshold value, then it is changed to 0 , while if it more than the threshold value then the value is changed to 255 .

\section{Model Pattern Development}

Localized Arc Pattern method is developed from Arc Pattern Method. Principal of this method shall be as follows: two final dot (point end) each $\mathrm{A}$ and of $\mathrm{B}$ connective by bows (such as those Figure 2) [10]. At the picture also can be seen five dot which a parting the same placed by above bow with characteristic dot (points characterizing). This dots later will compile pattern of utilized model as leaf characteristic.
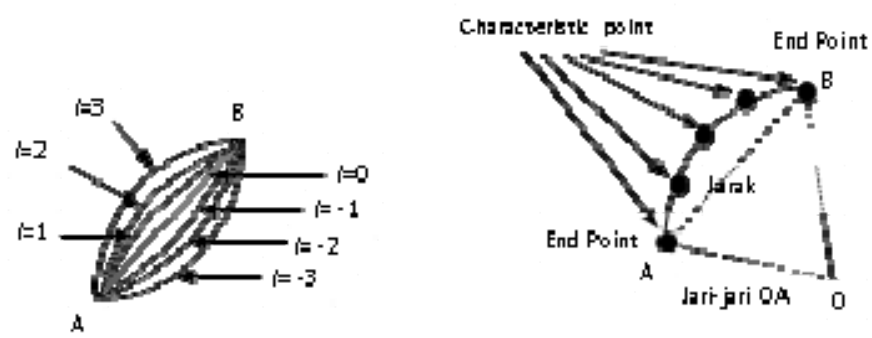

Fig. 2. Arc Pattern Method

Based Arc Pattern Method compiled a model which consist of one or two final end point and some dot among two final dot. That combination will yield model which a lot of, but for the actual system, not all model pattern utilized because it will make the system very slowly. This problem is overcome by reducing some of existing model pattern. One idea to realize reduction of this pattern model by localization problem to defined model pattern in small box 5 x 5 . Only model possibilities formed by characteristic dot in this square utilized as guidance to form model pattern. Arc Pattern method with this demarcation referred as with Localized Arc Pattern. Figure 3 shown model pattern that will be used to extraction leaves image. At the picture, number on the left show pattern number, while number on the right show model number. 


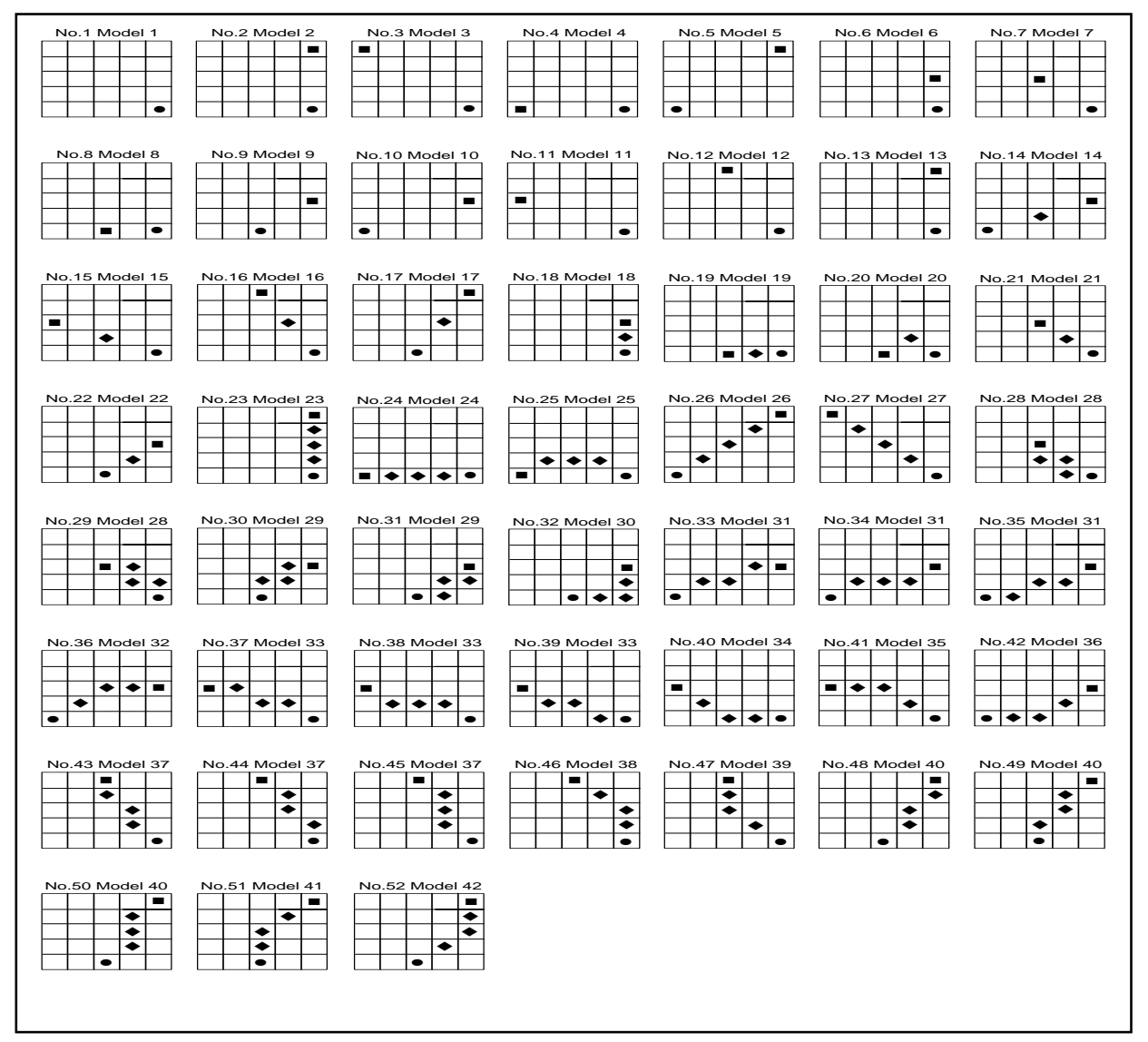

Fig. 3. Localized Arc Pattern Model

\section{Feature Extraction}

The binary vein image then processed by using 42 pattern models that obtained from the study of signature verification Indonesia [10] that shown in Figure 3.

Suppose that leaf image denoted by $f$ and there are 42 model patterns then the leaf image can be expressed as a column vector $x$ with dimension $p, p$ is 42 which is in accordance with the pattern of the existing model. In matrix form can be written as follows:

$$
X=\left[\begin{array}{c}
X_{1} \\
X_{2} \\
\vdots \\
X_{42}
\end{array}\right]
$$

The elements of $\mathrm{x}$ from $x_{1}, x_{2}, \ldots, x_{42}$ is occurrence frequency of each model pattern according to the model number.

\section{E. Enrollment}

Enrollment process for reference leaf is done by extracting feature of some reference leaves and the result is stored in a database. Suppose each image leaf $i^{\text {th }}$ is called Pi where it used as reference as much $m$, then $m$ pieces of leaves is extracted using Localized Arc Pattern method to generate $m$ pieces of column vector $x$ dimension $p$. The result is used as a matrix vector measuring $p \times m$ with form as follows: 


$$
P_{i}=\left[\begin{array}{cccc}
X_{11} & X_{12} & \cdots & x_{1 m} \\
X_{21} & X_{22} & \cdots & X_{2 m} \\
\vdots & \vdots & & \vdots \\
X_{p 1} & x_{p 2} & \cdots & X_{p m}
\end{array}\right]
$$

$M$ values used in this system is 60 leaves taken from some photos, with the consideration that the 60 leaves are expected to be able represent the variations of an image leaves, in addition, the system will work not too slow. Size of the vector matrix reference in this system is $42 \times 60$ for 42 pattern models. Vector matrix that obtained is stored in the reference database by keyword leaf id number.

\section{F. Comparison}

At comparison stage, the feature leaf image input will be compared with the reference feature that exist in the database. Based on comparison process the values obtained dissimilarity values (dissimilarity measure) each reference to the input image. Dissimilarity value or difference value is used as the basis for decision making recognition results.

$$
\begin{aligned}
D(P i, Q)= & \sum_{k=1}^{q} \frac{\left(Z_{Q}^{k}-Z_{/}^{k}\right)^{2}}{\lambda_{k}}+\sum_{k=q+1}^{p} \frac{\left(Z_{Q}^{k}-Z_{l}^{k}\right)^{2}}{\lambda_{q}} \\
& Z_{Q}^{k}=l_{k}^{t} X_{Q} \\
& Z_{/}^{k}=l_{k}^{t} X_{/}
\end{aligned}
$$

provided that $D\left(P_{i}, Q\right)$ is dissimilarity between the reference value of $P i$ with a comparator $Q, \lambda$ is column vector containing the eigenvalues in descending order $\left(\lambda_{1}, \lambda_{2}, \lambda_{3}, \ldots, \lambda_{p}\right), l_{k}$ is eigenvectors that shaped sequences column vector corresponding to the eigenvalues related, $x_{\mathrm{Q}}$ is a column vector containing the apparance frequency model pattern on the image of leaf compare, $\mathrm{x}_{/}$is average column vector reference, $t$ is transpose, $p$ is the dimension of the vector columns and $q$ is an integer with the proviso $1 \leq q \leq p$. The Constanta $q$ is cutting number of eigenvalues .

\section{G. Planning Database Reference}

The design phase of the reference database consists of two important points, there are the registration of reference leaves and determination of the threshold value. The registration process is continued by comparing leaf that is used to determine the threshold value. Based on the comparison results obtained value of these leaves dissimilarity. Median of dissimilarity value is stored in the reference database to complete the previous sample frequency, and is used as a threshold value or critical value that multiplied by Constanta $\mathrm{Cd}$.

\section{H. Decision making}

Dissimilarity values that obtained in the previous process is sorted. Reference identity with the smallest dissimilarity values and meet the threshold limit values decided as leaf type corresponding to the input image leaf. If the smallest dissimilarity values obtained are still above the threshold value, it is concluded leaf image input is not recognized.

\section{RESULT AND ANALYSIS}

As was explained previously, there are two main processes in this application that is the registration and recognition. This application must have leaves data for recognition. Table 1 shows the list of leaves that used on this experiment. 
ISSN (Print) : :2319-8613

ISSN (Online) : 0975-4024

TABLE 1.

List of Leaves Type

\begin{tabular}{|l|c|}
\hline \multicolumn{1}{|c|}{ Herbs Name } & Samples Total \\
\hline DadapSerap & 30 \\
\hline Guava & 30 \\
\hline Kumis Kucing & 30 \\
\hline Mengkudu & 30 \\
\hline Papaya & 30 \\
\hline Salam & 30 \\
\hline Samiloto & 30 \\
\hline Sirih & 30 \\
\hline Sirsak & 30 \\
\hline Sembung & 30 \\
\hline Total & $\mathbf{3 0 0}$ \\
\hline
\end{tabular}

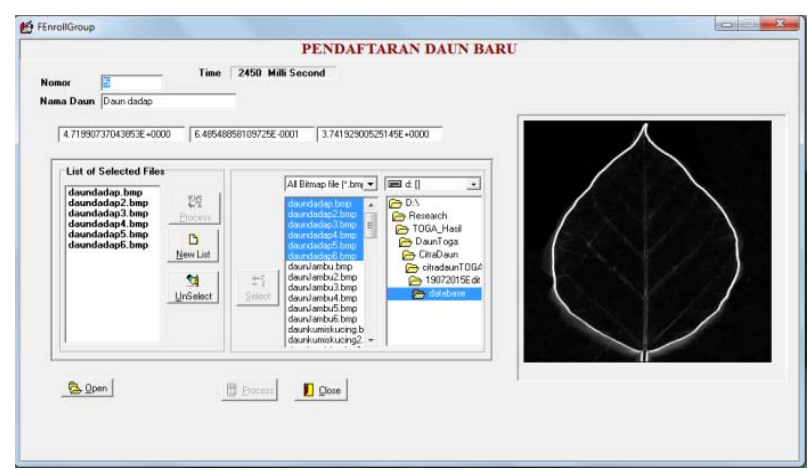

(a)

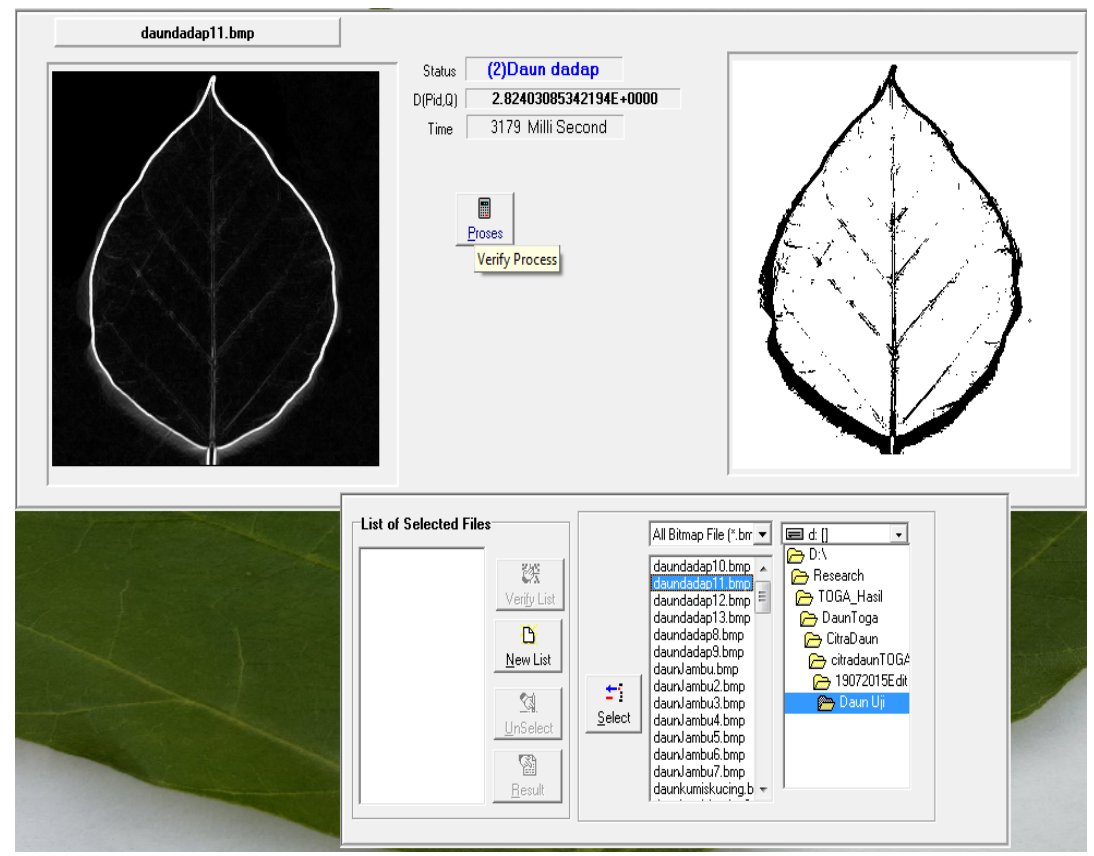

(b)

Fig. 4.(a) Recognition process, (b) Result herb recognition (Dadap image)

Figure 4a shows testing process of image Dadap leaves. This testing can test one of image or few image. On this testing the result was shown on Figure $4 \mathrm{~b}$. 


\section{Experiment Result}

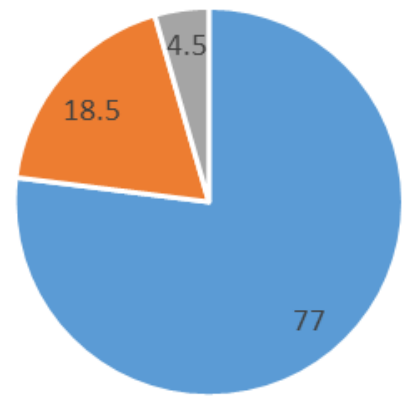

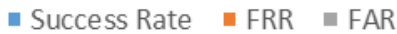

Fig. 5. Experiment result

Fig. 5 shows the match rate when recognition for each feature. The highest success rate of recognition is about 77\% with False Rejection Rate is $18.5 \%$ and False Accepted Rate is $4.5 \%$. Detail of experiment result shown on table 2 .

TABLE 2.

Experiment Result of Success Rate

\begin{tabular}{|c|c|c|c|}
\hline \multirow{2}{*}{ Herbal Name } & \multicolumn{3}{|c|}{ Recognition } \\
\cline { 2 - 4 } & $\begin{array}{c}\text { Success } \\
\text { Rate }\end{array}$ & FRR & FAR \\
\hline DadapSerap & 20 & 0 & 0 \\
\hline Guava & 20 & 0 & 0 \\
\hline Kumis Kucing & 20 & 0 & 0 \\
\hline Mengkudu & 16 & 0 & 4 \\
\hline Papaya & 20 & 0 & 0 \\
\hline Salam & 15 & 0 & 5 \\
\hline Samiloto & 8 & 12 & 0 \\
\hline Sirih & 20 & 0 & 0 \\
\hline Sirsak & 5 & 15 & 0 \\
\hline Sembung & 10 & 10 & 0 \\
\hline Persentage (\%) & $\mathbf{7 7}$ & $\mathbf{1 8 . 5}$ & $\mathbf{4 . 5}$ \\
\hline
\end{tabular}

Data in Table 2 shows the detail of success rate when recognition process. In this table, Salam and Sirsak give bad result for recognition. This is because the glossy leaf surface, so there is a lot of reflected light that become noise. Shape recognition give bad result on the leaves like Samiloto and Sembung because Samiloto has small size and leaf bone of Sembung is very thin so make a difficult process to find the feature. Based on research conducted using Localized Arc Pattern method for the introduction of palms produced an accuracy of $94 \%$, a research for the Herb Recognition using moment invariant method obtained only $68 \%$. It can be seen on Table 2 that Plant Recognition by using Localized Arc Pattern method with an accuracy of $77 \%$ have given a better result than invariant moment method.

\section{CONCLUSION}

In this paper made two important processes, there are Enrollment Process and Recognition Process. In each process the feature extraction done by using 42 model patterns. Based on the experiments, plant recognition is achieve $77 \%$ of success rate, FAR ( False Accepted Rate) equal to $4.5 \%$ and FRR ( False Reject Ratio) equal to $18.5 \%$. This result is influenced by glossy leaf surface, so there is a lot of reflected light that become noise. The match rate is also influenced by the shape of the leaf that make a difficult process to find the feature. 


\section{REFERENCES}

[1] Agus Suryawibawa, IKG Darma Putra, NKA Wirdiani. "Herbs Recognition Based on Android using OpenCV”. International Journal of Image Graphics and Signal Processing. 2015; 7(2): pp. 1-7.

[2] K. B. Lee and K. S. Hong. "An Implementation of Leaf Recognition System using Leaf Vein and Shape". International Journal of Bio-Science and Bio-Technology. 2013; 5(2): 57-66.

[3] A. Bhardwaj, M. Kaur, A. Kumar. "Recognition of plants by Leaf Image using Moment Invariant and Texture Analysis". International Journal of Innovation and Applied Studies. 2013; 3(1): 237-248.

[4] A. Kadir,L. E. Nugroho, A. Susanto, P. I. Santosa. "Experiments Of Zernike Moments For Leaf Identification". JATIT Journal of Theoretical and Applied Information Technology. 2012; 41(1): 82-93.

[5] Milan S. Image-based Recognition of Plants. Bachelor Thesis. Prague Postgraduate Czech Technical University. 2012.

[6] Trishen Munisami, Mahes Ramsurn, Somveer Kishnah, Sameerchand Pudaruth. "Plant leaf Recognition using shape features and colour Histogram with K-Nearest Neighbour Classifier". Procedia Computer Science. 2015; 58: 740-747.

[7] Jyotismita Chaki, Ranjan Parekh. "Plant Leaf Recognition using Shape based Features and Neural Network classifiers". International Journal of Advanced Computer Science and Applications. 2011; 2(10): 41-47.

[8] Pallavi, V.S Veena Devi. "Leaf Recognition Based on Feature Extraction and Zernike Moments". International Journal of Innovative Research in Computer and Communication Engineering. 2014; 2(2): 67-73.

[9] Dwi Rusjayanthi. "Identifikasi Biometrika Telapak Tangan Menggunakan Metode Pola Busur Terlokalisasi, Block Standar Deviasi, Dan K-Means Clustering”. Lontar Komputer. 2013. 265-276.

[10] Oka Sudana, AA.K. "Implementasi Pola Model Tandatangan Jepang dan Tandatangan Indonesia untuk Verifikasi Tandatangan Latin". Jurnal Pakar. 2007. 7 (4).

[11] Darma Putra. Pengolahan Citra Digital. Yogyakarta: CV. Andi Offset. 2010. 